\title{
Peningkatan Hasil Belajar Aljabar Linear Melalui Self Directed Learning Mahasiswa
}

\author{
Norma Puspitasari ${ }^{1 *}$, Arie Wahyuni ${ }^{2}$ \\ ${ }^{1}$ Politeknik Indonusa Surakarta, ${ }^{2}$ Universitas Ivet \\ *normasari@poltekindonusa.ac.id
}

Diterima: Agustus 2019. Disetujui: Desember 2019. Dipublikasikan: Januari 2020

\begin{abstract}
ABSTRAK
Peningkatan hasil belajar mahasiswa dapat diketahui melalui nilai akhir mahasiswa. Salah satu kemampuan afektif mahasiswa dapat dilihat melalui Self Directed Learning mahasiswa. Kemampuan kognitif mahasiswa dapat diukur melalui nilai UTS dan juga nilai UAS. Tingkat kognitif mahasiswa tidak sama sehingga pengukuran peningkatan hasil belajar mahasiswa memerlukan kecermatan dan ketelitian. Selain dari kemampuan kognitif mahasiwa peningkatan hasil belajar mahasiswa bisa di tinjau melalui Self Directed Learning mahasiswa dalam melaksanakan proses belajar mengajar. Aljabar linear merupakan salah satu mata kuliah dasar pada program studi D3 Manajemen Informatika yang mengarahkan mahasiswa mampu untuk menyelesaikan permasalahan matematis dalam kehidupan sehari-hari dan mampu untuk meningkatkan kemampuan berpikir matematis pada mahasiswa. Metode yang digunakan dalam penelitian ini adalah metode literatur, metode tes, dan metode dokumentasi dengan mengambil data volume nilai. Tujuan dari penelitian ini adalah untuk mengukur hasil belajar aljabar linear mahasiswa yang ditinjau dari Self Directed Learning mahasiswa. Jenis penelitian ini adalah penelitian deskriptif kuantitatif dengan teknis analisis data yang digunakan pada penelitian ini adalah anava dengan aplikasi SPSS. Hasil dari penelitian ini adalah terdapat pengaruh antara Self Directed Learning terhadap hasil belajar Aljabar Linear. Hal ini ditunjukkan bahwa ada perubahan nilai aljabar oleh Self Directed learning. Dalam proses analisis data dinyatakan pada nilai $\mathrm{p}$ value kurang dari 0,005 dan dengan persamaan regresi $\mathrm{Y}=0,009 \mathrm{X}+88,651$, dimana $\mathrm{Y}$ sebagai hasil nilai Aljabar Linear dan $\mathrm{X}$ sebagai Self Directed Learning. Dengan adanya analisis statistik tersebut dapat terlihat adanya peningkatan hasil belajar Aljabar Linear melalui Self Directed Learning, namun masih diperlukan pengembangan bahan ajar supaya pembelajaran bisa berjalan lebih efektif. Hasil dari penelitian ini adalah terdapat pengaruh antara Self Directed Learning terhadap hasil belajar Aljabar Linear, hal ini ditunjukkan bahwa ada perubahan nilai aljabar oleh Self Directed learning. Dalam proses analisis data dinyatakan pada nilai $\mathrm{p}$ value kurang dari 0,005 dan dengan persamaan regresi $\mathrm{Y}=0,009 \mathrm{X}+88,651$, dimana $\mathrm{Y}$ sebagai hasil nilai Aljabar Linear dan X sebagai Self Directed Learning. Dengan adanya analisis statistik tersebut dapat terlihat adanya peningkatan hasil belajar Aljabar Linear melalui Self Directed Learning, namun masih diperlukan pengembangan bahan ajar supaya pembelajaran bisa berjalan lebih efektif.

Kata kunci: hasil belajar, Self Directed Learning, Aljabar Linear.
\end{abstract}

\section{ABSTRACT}

Improved student learning outcomes can be known through the student's final grade. One of the affective abilities of students can be seen through Self-Directed Learning students. Student cognitive abilities can be measured through midterm grades and also midterm grades. Student cognitive levels are not the same, so measuring improvement in student learning outcomes requires precision and accuracy. Aside from the cognitive abilities of students the improvement in student learning outcomes can be reviewed through Self-Directed Learning students in implementing the teaching and learning process. Linear algebra is one of the basic courses in the D3 Informatics Management study program that directs students to be able to solve mathematical problems in their daily lives and is able to improve their mathematical thinking abilities. The method used in this research is the literature method, test method and documentation method by taking data volume values. The purpose of this study is to measure the results of student linear algebra learning in terms of Self-Directed Learning students. This type of research is a quantitative descriptive study with data analysis techniques used in this study is anava with SPSS applications. The results of this study are that there is an influence between Self Directed Learning on Linear Algebra learning outcomes, it is shown that there is a change in the value of algebra by Self Directed learning. In the process of data analysis expressed at $p$ value less than 0.005 and with the regression equation $Y=0.009 X+88.651$, where $Y$ is the result of Linear Algebra and $X$ as Self Directed Learning. From the statistical analysis, it can be seen an increase in Linear Algebra learning outcomes through Self Directed Learning, but the teaching materials need to be developed so the learning can run more effectively. The results of this study are that there is an influence between Self Directed Learning on Linear Algebra learning outcomes, it is shown that there is a change in the value of algebra by Self Directed learning. In the process of data analysis expressed at $p$ value less than 0.005 and with the regression equation $Y=0.009 X+88.651$, where $Y$ is the result of Linear Algebra and $X$ as SelfDirected Learning. With the statistical analysis it can be seen an increase in Linear Algebra learning outcomes through Self Directed Learning, but the development of teaching materials is still needed so that learning can run more effectively. Keywords: learning outcomes, Self Directed Learning, Linear Algebra.

How to Cite: Puspitasari, N. \& Wahyuni, A. (2020). Peningkatan Hasil Belajar Aljabar Linear Melalui Self Directed Learning Mahasiswa. Journal of Medives: Journal of Mathematics Education IKIP Veteran Semarang, 4(1), 181-186. 


\section{PENDAHULUAN}

Hasil belajar merupakan indikator yang terpenting dalam proses pembelajaran efektif. Pembelajaran efektif merupakan pembelajaran dengan adanya interaksi yang dilakukan peserta didik dengan pendidik dan sumber belajar agar tercapai hasil belajar (Wahyuni \& Kurniawan, 2018). Kualitas pembelajaran yang baik akan menghasilkan hasil belajar yang baik (Wulandari \& Surjono, 2013). Hasil belajar yang baik akan diperoleh jika adanya proses interaksi belajar yang saling ketergantungan antara dosen dan mahasiswa.

Menurut Hartati (2015) hasil belajar adalah perubahan tingkah laku siswa melalui aspek kognitif, aspek afektif, dan aspek psikomotorik. Hasil belajar adalah kemampuan yang dimiliki siswa setelah menerima pengalaman belajar (Sudjana, 2010). Dari pendapat diatas dapat disimpulkan bahwa hasil belajar merupakan perubahan tingkah laku siswa setelah menerima pengalaman belajar melalui aspek kognitif, aspek afektif, dan aspek psikomotorik.

Konsep matematika mengenai matriks dan vektor penting dalam ilmu komputer, dalam pembelajaran matematika merupakan materi dalam aljabar linear, sehingga mahasiswa perlu menguasai mata kuliah ini. Aljabar linear merupakan salah satu mata kuliah yang ada pada kurikulum program studi Manajemen Informatika Politeknik Indonusa Surakarta serta merupakan salah satu mata kuliah dasar yang menjadi prasyarat bagi mata kuliah yang lainnya. Penguasaan aljabar linear merupakan dasar bagi penguasaan beberapa mata kuliah lainnya (Apriyani,
2015). Pada mata kuliah aljabar linear dipaparkan materi dasar dari matematika yang dapat digunakan untuk merangsang konsep berpikir matematis mahasiswa dalam menyelesaikan permasalahan.

Hasil dari observasi terhadap pembelajaran mata kuliah aljabar linear selama ini dipengaruhi beberapa faktor diantaranya mahasiswa kurang diberi otonomi oleh dosen pada saat pembelajaran, pengajaran dosen masih model ceramah, dan dosen mengabaikan gaya belajar mahasiswa, hal tersebut disampaikan oleh dosen aljabar linear. Sehubungan beberapa faktor-faktor di atas agar meningkatkan hasil belajar mahasiswa, dosen perlu menggunakan aspek pembelajaran agar mahasiswa dapat merencanakan pembelajaran bagi dirinya sendiri. Salah satu aspek pembelajaran matematika yang dapat digunakan adalah self directed learning.

Self directed learning merupakan salah satu aspek afektif dalam pembelajaran matematika yang mengarahkan mahasiswa pada mengontrol kemampuan diri dalam menyelesaikan permasalahan. Ranah afektif menentukan keberhasilan belajar seseorang (Hairida \& Erlina, 2013). Karakteristik afektif yang mempengaruhi hasil belajar diantaranya sikap, minat, konsep diri, nilai, dan moral (Sariningsih \&Purwasih, 2017). Menurut Rachmawati (2010), self directed learning dapat mengatur proses belajar dalam bentuk inisiatif sendiri.

Self directed learning bersifat fleksibel yang berorientasi pada planning, monitoring, dan evaluating (Arjaya, 2013). Mahasiswa perlu menyadari kebutuhan belajarnya sehingga mahasiswa mampu bertanggung 
jawab terhadap hasil belajar yang didapat. Selain itu mahasiswa mampu untuk merumuskan tujuan belajar, mengidentifikasi sumber belajar, memilih dan menerapkan strategi belajar dan mengevaluasi hasil belajar. Pada pergantian tahun akademik terjadi peningkatan dan penurunan nilai pada mata kuliah aljabar linear. Untuk mengetahui perkembangan nilai tersebut setiap tahun yang dicapai mahasiswa diperlukan perhitungan statistik. Perhitungan statistik pada mata kuliah aljabar linear diperlukan juga untuk dosen supaya mengetahui perkembangan nilai pada tiap tahunnya dan dapat mengambil sebuah tindakan untuk menyelesaikan permasalahan yang mempengaruhi penurunan nilai.

\section{METODE PENELITIAN}

Pada tahap pertama adalah observasi nilai aljabar linear untuk tahun angkatan 2018/2019, setelah dari pengamatan ditemukan masalah dan akibatnya maka tahap kedua adalah pengumpulan data berkaitan dengan variabel-variabel yang digunakan, tahap ketiga adalah pengolahan data menggunakan software statistik yaitu SPSS Versi 16, tahap keempat adalah analisis data dan tahap kelima membuat suatu kesimpulan untuk mengambil sebuah keputusan.

Populasi pada penelitian ini adalah mahasiswa semester II tahun angkatan 2018/2019 sebanyak 82 mahasiswa. Cluster random sampling adalah teknik memilih sebuah sampel dari kelompokkelompok unit yang kecil. Metode OneStage Cluster Sampling membagi populasi menjadi kelompok atau kluster.
Sampel dalam penelitian ini adalah empat kelas dengan jumlah 57 mahasiswa dari populasi yang ada, perhitungannya adalah sebagai berikut.

$$
\begin{aligned}
& \mathrm{n}=\frac{\chi^{2} \mathrm{NP}(1-\mathrm{P})}{\mathrm{d}^{2}(\mathrm{~N}-1)+\chi^{2} \mathrm{P}(1-\mathrm{P})} \\
& =\frac{(1,841)(82)(0,50)(1-0,50)}{(0,05)^{2}(82-1)+(1,841)(0,50)(1-0,50)} \\
& =56,9=57
\end{aligned}
$$

Tabel 1. Sampel Mahasiswa

\begin{tabular}{ccc}
\hline No. & Kelas & $\begin{array}{c}\text { Jumlah } \\
\text { Proporsi }\end{array}$ \\
\hline 1. & Manajemen Informatika A & 19 \\
2. & Manajemen Informatika B & 17 \\
3. & Manajemen Informatika C & 12 \\
4. & Manajemen Informatika D & 9 \\
\hline
\end{tabular}

Instrumen yang digunakan adalah soal tes hasil belajar dan soal angket mengenai self directed learning. Self Directed Learning (SDL) termasuk dalam penilaian afektif terhadap mahasiswa, di mana indikator penilaian dari Self Directed Learning (SDL) adalah 1) siswa mengontrol banyaknya pengalaman belajar yang terjadi, 2) perkembangan keahlian, 3) mengubah diri pada kinerja/performansi yang paling baik, 4) manajemen diri siswa, 5) motivasi diri dan penilaian diri, 6) preplanning (aktivitas awal proses pembelajaran) 7) menciptakan lingkungan belajar yang positif, 8) mengembangkan rencana pembelajaran 9) mengidentifikasi aktivitas pembelajaran yang sesuai, 10) melaksanakan kegiatan pembelajaran dan monitoring, dan 11) mengevaluasi hasil belajar individu.

Teknik analisis data yang digunakan pada penelitian ini adalah Anava dengan aplikasi SPSS. 
HASIL DAN PEMBAHASAN

Hasil uji normalitas nilai akhir aljabar linear disajikan pada Tabel 2 .

Tabel 2. Uji Normalitas Nilai Akhir Aljabar Linear

One-Sample Kolmogorov-Smirnov Test

\begin{tabular}{lc}
\hline $\mathrm{N}$ & Nilai \\
\hline Normal Mean & 57 \\
Parameters Std. Deviation & 84.42 \\
Most Absolute & 5.398 \\
Extreme Positive & .105 \\
Differences Negative & .095 \\
Kolmogorov-Smirnov Z & -.105 \\
Asymp. Sig. (2-tailed) & .790 \\
\hline
\end{tabular}

a. Test distribution is Normal

Tabel 2 menunjukkan bahwa nilai sig $0,561>0.05$ sehingga data berdistribusi normal, sedangkan hasil uji normalitas nlai dari Self Directed Learning (SDL) dapat disajikan pada Tabel 3.

Tabel 3. Uji Normalitas SDL One-Sample Kolmogorov-Smirnov Test

\begin{tabular}{lc}
\hline & SDL \\
\hline $\mathrm{N}$ & 57 \\
Normal Mean & 89.42 \\
Parameters Std. Deviation & 3.300 \\
Most Absolute & .130 \\
Extreme Positive & .130 \\
Differences Negative & -.105 \\
Kolmogorov-Smirnov Z & .979 \\
Asymp. Sig. (2-tailed) & .293 \\
\hline
\end{tabular}

a. Test distribution is Normal

Tabel 3 menunjukkan bahwa nilai sig 0,293 $>0.05$ sehingga data berdistribusi normal. Hasil komputasi dari perhitungan regresi tersaji pada Tabel 4, 5 , dan 6 .
Tabel 4. Model Summary

\begin{tabular}{ccccc}
\hline Model & $\mathrm{R}$ & $\begin{array}{c}\mathrm{R} \\
\text { Square }\end{array}$ & $\begin{array}{c}\text { Adjusted } \\
\mathrm{R} \\
\text { Square }\end{array}$ & $\begin{array}{c}\text { Std. Error } \\
\text { of the } \\
\text { Estimate }\end{array}$ \\
\hline 1 & .015 & .000 & -.018 & 3.330 \\
\hline
\end{tabular}

a. Predictors: (Constant), Nilai

Tabel 5. ANOVA ${ }^{\mathrm{b}}$

\begin{tabular}{cccccc}
\hline Model & $\begin{array}{c}\text { Sum of } \\
\text { Squares }\end{array}$ & df & $\begin{array}{c}\text { Mean } \\
\text { Square }\end{array}$ & F & Sig. \\
\hline Regression & .136 & 1 & .136 & .012 & .912 \\
Residual & 609.759 & 55 & 11.087 & & \\
Total & 609.895 & 56 & & & \\
\hline
\end{tabular}

a. Predictors: (Constant), Nilai

b. DependentVariable: SDL

Tabel 6. Coefficients ${ }^{\mathrm{a}}$

\begin{tabular}{cccccc}
\hline \multicolumn{1}{c}{$\begin{array}{c}\text { Unstandardized } \\
\text { Coefficients }\end{array}$} & $\begin{array}{c}\text { Std } \\
\text { Coefficients }\end{array}$ & & \\
\hline Model & $\mathrm{B}$ & $\begin{array}{c}\text { Std. } \\
\text { Error }\end{array}$ & Beta & $\mathrm{t}$ & Sig. \\
\hline $\begin{array}{c}\text { (Constant) } \\
\text { Nilai }\end{array}$ & $\begin{array}{c}\text { 88.651 } \\
.009\end{array}$ & $\begin{array}{c}6.972 \\
.082\end{array}$ & .015 & .111 & .912 \\
\hline \multicolumn{2}{l}{ a. DependentVariable: SDL } & & & \\
\hline
\end{tabular}

Berdasarkan Tabel 6, uji pengaruh dengan SLD $=0.009$ nilai +88.651 memiliki Sig.0.912 $>0.05$ artinya bahwa terdapat peningkatan yang mempengaruhi secara signifikan antara self directed learning terhadap nilai aljabar linear. Hal ini sependapat dengan penelitian oleh Wahyuni (2018) yaitu terdapat pengaruh minat mahasiswa pada media pembelajaran maple terhadap hasil belajar secara signifikan. Penelitian ini juga didukung dari penelitian Hidayati (2017) bahwa penggunaan problem based learning berbasis self-directed learning oriented assessment efektif pada kemampuan pemecahan masalah.

Berdasarkan hasil statistik deskriptif diketahui bahwa dari 57 mahasiswa yang digunakan sebagai 
sampel diperoleh mean untuk nilai aljabar linear adalah 84,42 dengan nilai median $=85,00$, mode $=83$, hal ini menunjukkan nilai aljabar linear sudah memiliki rata-rata sudah tinggi. Penelitian ini didukung oleh penelitian Manggala, et al. (2013) bahwa hasil belajar matematika siswa dengan model self directed learning lebih baik daripada hasil belajar matematika siswa dengan model konvensional. Kemampuan kognitif mahasiswa sudah terukur dengan merata. Dan ditunjukkan pada kurva pada Gambar 1 yang berdistribusi normal.

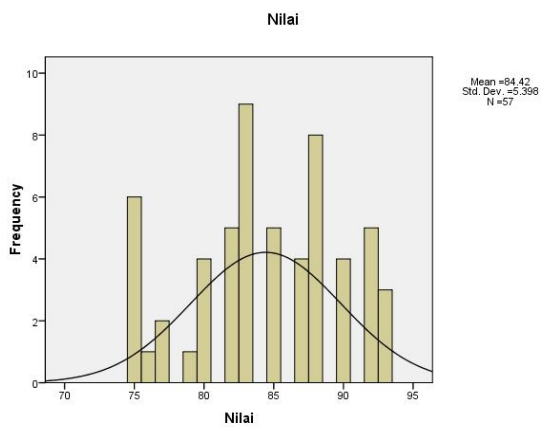

Gambar 1. Histogram Nilai

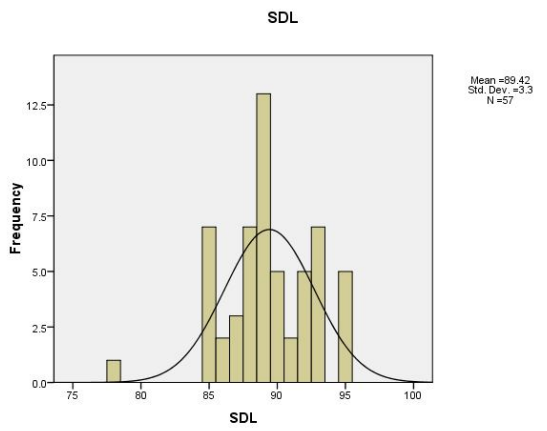

Gambar 2. Histogram SDL

Ditinjau dari self directed learning mahasiswa berdasarkan skor yang telah diolah didapat mean dari skor SDL adalah 89.42 , median $=89.00$ dan mode $=89$, hal ini menunjukkan skor dari nilai afektif pada SDL cukup tinggi. Hasil penelitian ini sejalan dengan penelitian Rusdi (2018) bahwa self directed learning berpengaruh positif terhadap hasil belajar matematika. Dan ditunjukkan pada kurva pada Gambar 2 yang berdistribusi normal.

\section{PENUTUP}

Ditinjau dari Self Directed Learning mahasiswa berdasarkan skor yang telah diolah didapat mean dari skor SDL adalah 89.42 , median $=89.00$ dan mode $=89$, hal ini menunjukkan skor dari nilai afektif pada SDL cukup tinggi. Dan ditunjuukan pada kurva yang berdistribusi normal.

Berdasarkan hasil olahan data menggunakan SPSS terlihat bahwa terdapat pengaruh antara Self Directed Learning terhadap Hasil belajar Aljabar Linear, hal ini ditunjukkan bahwa ada perubahan nilai aljabar oleh Self Directed learning. Dalam proses analisis data dinyatakan pada nilai $p$ value kurang dari 0,005 dan dengan persamaan regresi $\mathrm{Y}=0,009 \mathrm{X}+88,651$, dimana $\mathrm{Y}$ sebagai hasil nilai Aljabar Linear dan $X$ sebagai Self Directed Learning.

Penggunaan SPSS dalam perhitungan nilai aljabar linear pada D3 Manajemen Informatika Politeknik Indonusa Surakarta dapat memenuhi semua kebutuhan statistik dengan statistik tersebut diharapkan dapat sebagai peningkatan nilai dari masingmasing mahasiswa, karena jika dilihat perbedaan nilai setiap semester dapat disimpulkan nilai mahasiswa yang menurun atau meningkat, dan dapat lebih spesifik lagi dilihat dari data per kelas, jadi dosen dapat mengetahui perbandingan nilai per kelas. 
DAFTAR PUSTAKA

Apriyani, D. C. N. (2015). Upaya Meningkatkan Motivasi dan Prestasi Belajar Mahasiswa Dengan Pembelajaran Kooperatif Tipe Thinking Aloud Pairs Problem Solving Pada Mata Kuliah Aljabar Linear. Beta: Jurnal Tadris Matematika, 8(2), 142-152.

Arjaya, I. B. A. (2013). Model Self Directed Learning Berbasis Lingkungan Dalam Pembelajaran Biologi. In Proceeding Biology Education Conference: Biology, Science, Environmental, and Learning. (Vol. 10, No. 1)

Hairida, H., \& Erlina, E. (2013). Korelasi Antara Self-Efficacy Dengan Hasil Belajar Siswa Dalam Mata Pelajaran Kimia di SMA. Jurnal Pendidikan dan Pembelajaran Untan, 2(9).

Hartati, L. (2015). Pengaruh Gaya Belajar dan Sikap Siswa Pada Pelajaran Matematika Terhadap Hasil Belajar Matematika. Formatif: Jurnal Ilmiah Pendidikan MIPA, 3(3).

Hidayati, D. W. (2017). Penerapan Problem Based Learning Berbasis Self-Directed Learning Oriented Assessment Terhadap Kemampuan Pemecahan Masalah. Journal of Medives: Journal of Mathematics Education IKIP Veteran Semarang, 1(1), 17-24.

Manggala, I. K. A., Suarni, N. K., \& Suarjana, I. M. (2013). Pengaruh Model Pembelajaran Self Directed Learning Terhadap Hasil Belajar Matematika Siswa Kelas IV SD Lab Undiksha Singaraja Tahun Pelajaran 2012/2013. Mimbar PGSD Undiksha, 1(1).
Rachmawati, D. O. (2010). Penerapan Model Self-Directed Learning Untuk Meningkatkan Hasil Belajar dan Kemandirian Belajar Mahasiswa. Jurnal Pendidikan dan Pengajaran, 43(3).

Rusdi, M. (2018). Pengaruh SelfDirected Learning dan Disposisi Matematis Terhadap Hasil Belajar Matematika Siswa (Doctoral Dissertation, Universitas Negeri Makassar).

Sariningsih, R., \& Purwasih, R. (2017). Pembelajaran Problem Based Learning Untuk Meningkatkan Pemecahan Masalah Matematis dan Self Efficacy Mahasiswa Calon Guru. JNPM (Jurnal Nasional Pendidikan Matematika), 1(1), 163177.

Sudjana, Nana. (2010). Penilaian Hasil Proses Belajar Mengajar. Bandung: PT. Ramaja Rosdakarya.

Wahyuni, A., \& Kurniawan, P. (2018). Efektivitas Pendekatan Problem Based Learning (PBL) Berbasis ICT Pada Mata Kuliah Kalkulus Lanjut. In Prosiding Seminar Nasional Matematika dan Pendidikan Matematika $\quad\left(3^{\text {th }} \quad\right.$ SENATIK): Universitas PGRI Semarang.

Wahyuni, A. (2018). Pengaruh Penggunaan Maple Sebagai Media Pembelajaran Pada Mata Kuliah Kalkulus Lanjut. In Prosiding Seminar Nasional \& Internasional (Vol.1, No.1).

Wulandari, B., \& Surjono, H. D. (2013). Pengaruh Problem-Based Learning Terhadap Hasil Belajar Ditinjau Dari Motivasi Belajar PLC di SMK. Jurnal Pendidikan Vokasi, 3(2). 